\title{
Demand Market Matrix Analysis of High-speed Railway Tourism Development in Jilin Border Area
}

\author{
Haiyang Liu ${ }^{1,2}$ \\ ${ }^{1}$ Institute of History and Culture, Changchun Normal \\ University \\ ${ }^{2}$ The Northeast Institute of Geography and Agroecology \\ Chinese Academy of Sciences \\ Changchun, China \\ haiyang0796@163.com
}

\begin{abstract}
The construction of high-speed railway has brought great convenience to people's travel. Its speed strengths, safety strengths, and large passenger capacity have become an important factor in promoting the development of tourism. After the opening of the high-speed railway, it has brought huge passenger traffic to tourism destinations and has had a profound impact on the development of the tourism industry. This paper aims at the construction of high-speed railways along the Jilin Province and uses the ASEB-SWOT grid analysis method to analyze and study the changes in the activities, setting, experiences, and benefits brought about by the construction of high-speed railway from four aspects of strengths, weaknesses, opportunities, and threats, and provide intellectual support for the development of the border tourism in Jilin Province under the influence of high-speed railway.
\end{abstract}

Keywords-ASEB-SWOT; high - speed railway; tourism industry; border area

\section{INTRODUCTION}

On December 30, 2010, the Changji Intercity railway, the first high-speed railway in the northeast, was opened and operated. The railway has a total length of 108.16 kilometers. It is a major transportation infrastructure project in the "Eleventh Five-Year Plan" of Jilin Province. There are totally four stations of this railway, which respectively are Changchun, Longjia, Jiutai South, and Jilin station. The construction of Changji High-speed railway has played a leading role in enhancing the industrial diffusion of the two central cities of Changchun and Jilin.

Two years later, on December 1, 2012, the Harbin-Dalian High-speed railway was opened, and a second high-speed railway appeared on Jilin. This is also the world's first railway distributed in the extremely cold area and runs through the three northeastern provinces. While Jilin Province is on a transit station across the country, the new plan for the city's onsite city will be based on high-speed railways to build botanical gardens, parks, and leisure resorts, attracting a large number of tourists.

On September 20, 2015, the Ketubang high-speed railway was officially opened, ending the history of no high-speed trains in the eastern part of Jilin Province, further promoting the transportation links between the hinterland of Jilin and the Tumen River region, accelerating the development and construction of the Chang-Ji-Tu region, and promoting the tourism development in Tumen River and Changbai Mountain areas [1]. The development of tourism in the eastern border areas of Jilin entered the high-speed railway era.

\section{ASEB-SWOT MATRIX ANALYSIS}

\section{A. SWOT Analysis}

SWOT analysis was proposed by Steiner, an American management scientist. It refers to the analysis of the company's internal and external setting, resources, and strategic capabilities to find out key factors and systematically identify the internal strengths, weaknesses, opportunities, and threats. Among them, strengths and weaknesses are internal factors, and the factors that are inherent in themselves. Opportunities and threats are external causes. SWOT analysis is an objective analytical method that has been used in many fields. This method can be used to conduct a comprehensive, systematic, and accurate research on the situation of the research object, comprehensively analyze the internal conditions and the external setting of the regional tourism, formulate or revise the development strategy, strive to turn weaknesses into strengths and turn threats into opportunities under the guidance of a rational strategy model.

SWOT is the combination of the first letter of Strength, Weaken, Opportunity, and Threat. It is a common method for the targeted analysis of the research object in the setting from the above four aspects in the modern marketing. Among them, strengths are understood as the superiority, strengths, characteristics, and strengths of the research object in a certain setting; weaken should be understood as weaknesses, shortcomings, and deficiencies of research subjects in a certain setting; opportunity should be understood as the favorable development trend and directions of the research object in a certain setting; threats should be understood as the substitution of the research object in a certain setting, which are often based on the analysis of competitors. 


\section{B. ASEB-SWOT grid analysis}

The ASEB grid analysis method is a market analysis method based on consumer demand. It incorporates consumer experience into the scope of analysis and attaches great importance to the analysis of various situations of the project from the perspective of consumers, and it is well-targeted for analyzing problems caused by experiential consumption.

ASEB (Activity, Setting, Experience, Benefit) combines Manning-Hass-Driver-Brown's needs-level analysis, namely activities, settings, experiences, and benefits, with SWOT analysis's different elements to form a matrix of 16 units. The 16 units were sequentially analyzed from the SA (advantage evaluation of activities) to the TB (threat assessment of benefits). ASEB grid analysis method analyzes and evaluates the strengths, weaknesses, opportunities, and threats of activities, settings, experience, and benefits from the perspective of consumers, understands consumer behavior, and plans and improves projects to better meet the needs of consumers.

Combining the ASEB analysis with SWOT analysis, a new matrix diagram is formed, as shown in the following table:

TABLE I. ASEB-SWOT GRID ANALYSIS MATRIX

\begin{tabular}{|c|c|c|c|c|}
\hline & Activity & Setting & Experience & Benefit \\
\hline Strengths & SA & SS & SE & SB \\
\hline Weaknesses & WA & WS & WE & WB \\
\hline Opportunities & OA & OS & OE & OB \\
\hline Threats & TA & TS & TE & TB \\
\hline
\end{tabular}

III. A SWOT ANALYSIS OF HIGH-SPEED RAILWAY TOURISM BASED ON ASEB MARKET ORIENTATION

\section{A. Strengths}

\section{1) Strengths of the activities (SA)}

It is said that Yanbian is a gorgeous place. There is a fascinating view of the Changbai Mountains and a strong Korean customs. The constantly improving infrastructure and rich tourism products will gradually transform the advantages of resources here into the advantages of tourism. After the opening of the Ji-Hui High-speed railway, tourists choose Yanji as the first choice for travel destinations. They can go back on the same day with a different mood. The development of tourism that is in line with the international standard in Yanbian, the favorable geographic conditions, visas for border crossings, one day passport and other measures that facilitate travel have attracted tourists from all directions and Northeast Asian countries to carry out tourism cooperation, which has the vigorous development of tourism in Yanbian and even our province [2]. International tourism has already formed a new upsurge in China. Last year, the national tourist population was 100 million millions. Among the more than 100 million tourism population, tourism in Japan, South Korea, Russia, and Mongolia of Northeast Asia occupied a large proportion, which is a driving and driving force for Yanbian and Jilin Province. As a pillar industry, tourism economic development must have the international regional cooperation component of Northeast Asia, so as to truly become the pillar of our province.

\section{2) Strengths of the setting(SS)}

The development of the Changbai Mountain area in Jilin Province is in good condition. At present, it still maintains the original appearance of nature and has a unique style of scenery. It has become a world-famous mountain range with its abundant and magical original features. For people growing up in the city from an early age, nature is very attractive to them. Changbai Mountain's resource mix is relatively good, and mountain and view is pretty beautiful there. In addition, the strengths and weaknesses of Changbai Mountain's tourism resources and the combination of environmental protection is clearly defined, which will promote the development of tourism and ecological environmental protection, and will be infinitely popular all year round. The construction of highspeed railways has increased the fluency of traffic, enabling tourists to get a good diversion and reduce the damage to the tourism resources and setting of Changbai Mountain during the tourist season.

\section{3) Strengths of the experience(SE)}

The era of high-speed railway is an era toward rapid development. In the high-speed railway era, tourists are choosing an experience while choosing high-speed railway. The characteristics of the high-speed railway have been explained to everyone in the previous quarters. People can travel under comfortable conditions, which is exactly the strengths the high-speed railway can bring us from the perspective of experience[2]. A number of high-speed railway lines run through Jilin Province, giving Jilin Province new vitality and making tremendous contributions to the sound and rapid development of the tourism economy in Jilin Province.

\section{4) Strengths of the benefits(SB)}

Ji-Hui High Speed railway officially opened and operated on September 20, 2015. During the 11th Golden Week holiday of that year, the Yanbian tourism market was unusually fiery. In a short span of several days, it received 733,000 tourists with a total tourism income of 1.161 billion Yuan. The staffs engaged in the tourism industry for many years were delighted. This shows that the high-speed railway plays an important role in the growth of tourism economy.

\section{B. Weaknesses}

\section{1) Weaknesses of the activities(WA)}

In Jilin Province, historically, traffic was underdeveloped, and exchanges with other cities were not extensive, tourism resources lack brand effect and influence and cultural heritage such as historical relics and relics is not deep enough. In addition, the number of experts and scholars in the relevant departments is small, and the research on this aspect is also very rare, which is conductive to the tourism industry in Jilin Province.

\section{2) Weaknesses of the setting(WS)}

The construction of high-speed railways will inevitably lead to a large influx of people. Tourists from all regions will come to visit from time to time, which has a tremendous negative impact on the natural resources of Jilin Province. After the opening of the high-speed railway, tourists from all directions flocked and gathered together. The environmental carrying capacity and other aspects are facing great threats, 
such as destruction of vegetation, trampling of scenic areas, domestic garbage, and other human factors [3]. In addition, the sudden arrival of huge numbers of tourists will also put severe challenges for accommodation destinations, hotels, restaurants, etc.

\section{3) Weaknesses of the experience(WE)}

One of the deficiencies in tourism in Jilin Province is that brand influence is not obvious enough. In other provinces where high-speed trains are also opened, the overall strength of local tourism products is relatively strong. In contrast, tourists will lose confidence in the tourism experience in Jilin Province, which is not conducive to the development of the tourism industry in Jilin Province. Although the construction of highspeed railways has increased the passenger flow in Jilin Province, it still cannot meet the demand of tourists.

\section{4) Weaknesses of the benefits(WB)}

As a family with a lower standard of living, the price will be attached the most importance when traveling. Although the high-speed railway makes us feel pleasant and comfortable and is time-saving, a large part of people will consider the price factor. For example, the price for ordinary trains from Dalian to Changchun is 80 Yuan, the price for first-class seats in highspeed railway is 487 Yuan and the price for second-class seats is 304 Yuan. By comparison, the price of high-speed railway far exceeds that of ordinary trains, which are more than six times and nearly four times of the normal train prices. Therefore, in this respect, the construction of high-speed railway is an obstacle to the development of tourism in Jilin Province.

\section{Opportunities}

\section{1) Opportunities of the activities $(O A)$}

The high-speed railway era has drawn close contact with various provinces and cities with its speed[4]. The Agricultural Fair, the Employment Exhibition Center, and the unique folk festivals in Yanbian region, etc., which are launched in Jilin Province, are passed to the vast number of people along the line through high-speed railway transportation, and promote the development and growth of the tourism industry in Jilin Province.

\section{2) Opportunities of the setting(OS)}

The high-speed railway extending in all directions brings opportunities for the development of the tourism industry in Jilin Province. With the increase in the number of visitors and experience, the demand for tourism products also increases. The tourism industry in Jilin Province should give full play to its own advantages, coupled with the promotion of the construction of high-speed railways, to develop better and more characteristic tourism products and enhance the environmental advantages of tourism in Jilin Province though the interaction between natural eco-tourism resources and cultural tourism resources.

\section{3) Opportunities of the experience $(\mathrm{OE})$}

The opening of a wide range of high-speed railway lines has provided us with a good number of tourists, while it is also accompanied by the flow of funds, the flow of culture, the flow of science and technology, the flow of information, and so on, through which tourists are given opportunities to experience and increase their sense of satisfaction.

\section{4) Opportunities of the benefits $(O B)$}

Because of the opening of the high-speed railway, various travel agencies in Changchun, Jilin Province have also expanded their markets to contact local travel agencies in other parts of Jilin Province. [5] So far, travel agencies in Yanbian have opened 34 branch offices in Changchun. Travel agencies have seized the opportunity that the high-speed railway service has brought good and fast development to the hometown. The opening of the high-speed railway has changed the time and space of the tourism industry and tourism product portfolio in Jilin Province. Our province can take advantage of the opportunity of high-speed railway construction to fully play its role and re-assemble new products to provide tourists with more diverse travel options. In addition, the promotion of the border tourism will provide interests and benefits for all aspects of tourism revenue in Jilin Province.

\section{Threats}

\section{1) Threats of the activities(TA)}

In contrast, the development of the tourism industry in Jilin Province is still relatively backward, the maturity of tourism products is low, the brand appeal is not obvious, and there is still a need to continue to improve the satisfaction of tourists. Although the development of high-speed railway construction can increase the time for tourists to travel around their destinations, as the number of trips increases, people will lose interest in tourism products that do not have a greater brand appeal [6], thus threatening the development of the tourism industry in Jilin Province.

\section{2) Threats of the setting(TS)}

The opening of high-speed trains increased the number of running trains. Although the pollution is lighter than other modes of transport, it is accompanied by slight noise, vibration, obsolescence, and radiation, affecting residents' environmental life[7]. On the other hand, it has intensified the impact of various aspects to a certain extent, such as the flow of people, the amount of information, and the flow of materials. However, the relevant supporting facilities in Jilin Province have not been improved in a timely manner. The development of each aspect of "food, housing, transport, tourism, entertainment and shopping” needs to be improved. Therefore, in the face of a sudden and huge increase in passenger traffic, it can not afford it and the leading role of the tourism industry is not obvious.

\section{3) Threats of the experience(TE)}

With the promotion of high-speed railway construction, the level of tourists' demand for tourism products has increased However, the operation of tourism products in Jilin Province lacks the operation of large companies and does not mobilize the participation of local people, resulting in a low level of local tourism market.

\section{4) Threats of the benefits(TB)}

The main threat to high-speed railway is expensive ticket prices. Relative to the train, the price elasticity of the plane is relatively large, and its attractiveness is also great. The reduction in the price of the plane will definitely lead to an 
increase in the number of passengers on the plane. Therefore, the interests of high-speed railway in this respect exist.

\section{CONCLUSION}

In today's society, people's material conditions are abundant, so in the limited time, the time spent on the road during travel will be particularly important. Although the price of high-speed railway is three times that of ordinary trains, considering the time factor, we often choose high-speed railways to reduce the waste of time. The cost of travel includes the time cost, and the travel time of the traveler includes the time of play and travel time. Increasing travel time and reducing travel time are ways for visitors to maximize their profits. In addition, when the ease of transportation of a tourist destination in a region cannot achieve the purpose of enhancing tourist attraction in this region, the tourists' interest in tourism will largely shift to other regions where the transportation is relatively convenient. Therefore, transportation facilities are one of the important factors that affect tourists' travel.

The Ji-Hui High-speed railway runs from Jilin City in the east to Hunchun City in the west, covering Jilin, Jiaohe, Dunhua, Antu, Longjing, Yanji, Tumen and Hunchun eight cities and has a total length of 360 kilometers, which has greatly shortened the time distance between the eastern border areas of Jilin and major tourist destinations, further improved the railway network in the Northeast, strengthened the transportation links between the surrounding areas of Jilin City and Yanji and Tumen, accelerated the construction of ChangJi-Tu's development pilot area, and promoted the development of international tourism in Tumen River area and Changbai Mountain area.

Fund Project: This paper is the funding results of "Changbai Mountains Nature and Humanities" theme guiding project of Jilin Province Natural Science Foundation -- "Study on the Relationship between Ethnic Group Changes and Natural Environment Response in the Border Areas of Changbai Mountain"(20170101012JC), "13th Five-Year Plan" Social Science Research Project of Jilin Provincial Department of Education -- "Jilin Province Border Tourism Development Model and Product Innovation Research” (JJKH20181197SK) and Humanities and Social Sciences Research Fund Project of Changchun Normal University -- "Study on the Symbiosis Development Model of Border Tourism"(20160211).

\section{REFERENCES}

[1] LIU Hai-yang. Influence of High Speed railway on the Development of Border Area' s Tourism Business in Jilin Province[J]. Journal of Dalian University, 2017,38(06):88-93.(In Chinese)

[2] Wang D, Yu N, Sun F, et al. Evolution and spatial characteristics of tourism field strength of cities linked by high-speed railway (HSR) network in China[J]. Journal of Geographical Sciences, 2017, 27(7):835856.

[3] Cartenì A, Pariota L, Henke I. Hedonic value of high-speed railway services: Quantitative analysis of the students' domestic tourist attractiveness of the main Italian cities[J]. Transportation Research Part A Policy \& Practice, 2017, 100:348-365.

[4] Sun Y Y, Lin Z W. Move fast, travel slow: the influence of high-speed railway on touris $\mathrm{m}$ in Taiwan[J]. Journal of Sustainable Touris $\mathrm{m}$, 2017(1):1-18.

[5] Liu Y, Shi J. How inter-city high-speed railway influences tourism arrivals: evidence from social media check-in data[J]. Current Issues in Tourism, 2017(2):1-18.

[6] Jiang C, Zhang A. Effects of high-speed railway and airline cooperation under hub airport capacity constraint[J]. Transportation Research Part B, 2014, 60(2):33-49.

[7] Guo J, Wang S, Li B, et al. The Spatial Effect of Harb in-Dalian Highspeed railway to the Northeast City Tourism Economic Lin $\mathrm{k}[\mathrm{J}]$. Scientia Geographica Sinica, 2016, 36(4):521-529. 